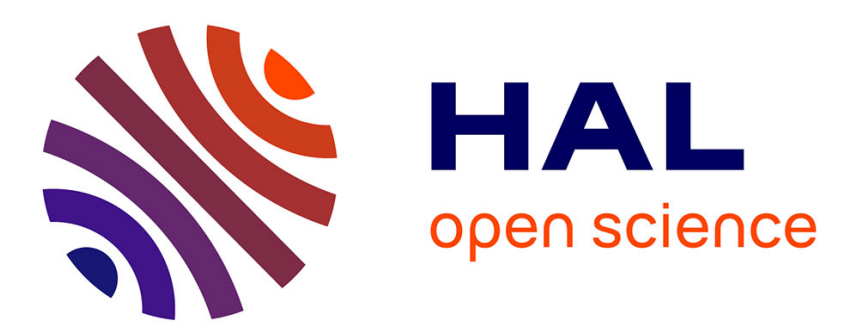

\title{
Individual Responsibility and the Funding of Collective Goods
}

Louis Lévy-Garboua, Claude Montmarquette, Marie Claire Villeval

\section{To cite this version:}

Louis Lévy-Garboua, Claude Montmarquette, Marie Claire Villeval. Individual Responsibility and the Funding of Collective Goods. 2007. halshs-00174557

\section{HAL Id: halshs-00174557 https://shs.hal.science/halshs-00174557}

Submitted on 24 Sep 2007

HAL is a multi-disciplinary open access archive for the deposit and dissemination of scientific research documents, whether they are published or not. The documents may come from teaching and research institutions in France or abroad, or from public or private research centers.
L'archive ouverte pluridisciplinaire HAL, est destinée au dépôt et à la diffusion de documents scientifiques de niveau recherche, publiés ou non, émanant des établissements d'enseignement et de recherche français ou étrangers, des laboratoires publics ou privés. 


\section{Individual Responsibility and the Funding of Collective Goods}

Louis Lévy-Garboua, Claude Montmarquette, Marie-Claire Villeval

Septembre 2007

GATE Groupe d'Analyse et de Théorie Économique UMR 5824 du CNRS

93 chemin des Mouilles - 69130 Écully - France

B.P. 167 - 69131 Écully Cedex

Tél. +33 (0)4 72866060 - Fax +33 (0)4 72866090

Messagerie électronique gate@gate.cnrs.fr

Serveur Web : www.gate.cnrs.fr 


\title{
Individual Responsibility and the Funding of Collective Goods
}

\author{
Louis Lévy-Garboua ${ }^{a}$ \\ Claude Montmarquette \\ Marie-Claire Villeval ${ }^{\mathrm{c}}$
}

\begin{abstract}
When a deficit occurs in the funding of collective goods, it is usually covered by raising the amount of taxes or by rationing the supply of the goods. This article compares the efficiency of these institutions. We report the results of a $2 \times 2$ experiment based on a game in the first stage of which subjects can voluntarily contribute to the funding of a collective good that is being used to compensate the victims of a disaster. In the second stage of the game, in case of a deficit, we introduce either taxation or rationing. Each treatment is subjected to two conditions: the burden of the deficit is either uniform for all the subjects, or individualized according to the first-stage contribution. We show that the individualized treatments favor the provision of the collective good through voluntary cooperation whereas the uniform treatments encourage free-riding. Individualized taxation brings the voluntary contributions closer to the optimum while uniform rationing appears to be the worst system since free-riding restrains the provision of the good.

Résumé: Un déficit dans le financement d'un bien collectif est généralement couvert soit par un accroissement des impôts, soit par un rationnement des usagers. Cet article compare l'efficacité de ces institutions. Nous présentons les résultats d'une expérience de laboratoire qui s'appuie sur un jeu dans la première étape duquel les sujets peuvent contribuer volontairement au financement d'un bien collectif destiné à indemniser les victimes d'un dommage. Dans la deuxième étape du jeu, en cas de déficit, nous introduisons soit un impôt, soit un rationnement. Chaque traitement est soumis à deux conditions: la prise en charge du déficit est soit uniforme pour tous les sujets, soit individualisée en fonction de la contribution volontaire du sujet en première étape. Nous montrons que les traitements individualisés favorisent la provision du bien collectif grâce à la coopération volontaire, alors que les traitements uniformes encouragent le comportement de passager clandestin. L'impôt individualisé rapproche les contributions volontaires de l'optimum, tandis que le rationnement uniforme est la pire institution puisque le comportement de passager clandestin restreint la provision du bien.
\end{abstract}

JEL-Codes: H41, H21, H30, H50, C91.

Keywords: Collective goods, taxation, rationing, responsibility, interior optimum, experiment.

Mots clés: bien collectif, fiscalité, rationnement, responsabilité, optimum intérieur, experience. 
a CES-TEAM and Paris School of Economics, Université de Paris I, 106-112 Bd de l'Hôpital 75647 Paris Cedex 13, France, and CIRANO, Montreal, Canada. Louis.Levy-Garboua@univparis1.fr

${ }^{\mathrm{b}}$ CIRANO and Université de Montréal, 2020 rue University, Montreal, (Quebec), Canada, H3A 2A5. Claude.Montmarquette@cirano.qc.ca.

c GATE; CNRS; University of Lyon; 93, chemin des Mouilles F-69130 Ecully, France, and Institute for the Study of Labor (IZA), Bonn, Germany. villeval@gate.cnrs.fr

We are grateful to Mark Isaac and participants at several conferences and seminars for helpful comments. We also thank Romain Zeiliger for programming the experiment presented in this article and Nathalie Viennot for research assistance. Financial support from the French Ministry of Research (ACI Inter-SHS) and the Government of Québec is gratefully acknowledged. 


\section{INTRODUCTION}

There are instances in which members of a group or society are confronted to the same basic need in their lifetime but do not face it simultaneously. For example, all families will need to send their young children at school and all persons suffering from diseases will need health care. Over a great number of periods, such needs will be felt with near certainty. In a given period, however, the distribution of needs in a large population might be considered random. Consequently, privately consumed goods and services of this sort can be mutually funded like an insurance policy in order to take advantage of risk diversification. Redistributive taxation and rationing are two widely used policies for financing such collective goods. In the first case, the optimal provision of the good is guaranteed but the deficit generated by the insufficient level of voluntary contribution is funded by compulsory taxes at an additional cost for society. In the second case, the collective good is provided only to the extent that it has been voluntarily funded by group members. The budget constraint is always met at the cost of possibly providing the collective good at a suboptimal level. Taxation adjusts aggregate contributions to the socially desirable consumption level, while rationing adjusts aggregate consumption to the sum of voluntary contributions. In any case, however, redistribution generally occurs. This has the effect of blurring the relation between the price paid by each individual to satisfy his need and the marginal utility of the collective good, at the expense of efficiency.

The goal of this paper is to compare the efficiency of various modes of redistributive taxation and rationing in the provision of collective goods. Specifically, we introduce uniform and individualized modes of both taxation and rationing policies. Uniform and individualized modes reflect different conceptions of equity: the former value equal treatment a priori whereas the latter value equal outcomes a posteriori. By crossing two policies (taxation, rationing) with two modes 
(uniform, individualized), we are able to compare four different institutions that are widely used for funding collective goods. We question here the ability of these institutions to give individuals a sense of "responsibility" by letting them spontaneously come closer to efficiency.

For this purpose, we have designed a laboratory experiment based on a two-stage collective good (insurance) game. We observe individual contribution behavior when private needs are met collectively and prices are not expressed on a market. ${ }^{1}$ In the first stage, subjects receive an endowment and voluntarily contribute to a common pool intended to compensate for the losses suffered by those members of the group who happen to be randomly hit at the beginning of the second stage. In the second stage, two situations may occur. If the losses can be fully or more than fully covered by voluntary contributions in the aggregate, each victim can be totally compensated and any surplus is burnt. On the other hand, if the voluntary contributions fall short of the losses to be covered in the aggregate, four different solutions for equalizing the supply of funds and the demand for compensation are being considered. Uniform policies offer equal treatment of group members in the second stage (ex post), irrespective of their individual effort in the first stage (ex ante). In contrast, individualized policies offer a differentiated treatment of group members in the second stage, specifically favoring those who contributed most in the first stage. Thus, four institutions are considered in the second stage in a $2 \times 2$ experimental design. We describe them respectively as uniform taxation, individualized taxation, uniform rationing and individualized rationing.

The four treatments share the same social optimum of "equal contribution for all". However, they lead to very different Nash equilibria: no contribution for uniform policies, an interior

\footnotetext{
${ }^{1}$ Olson (1965), Dawes and Thaler (1988) and Ostrom (1990) have shown how, in this context of collective action, it is tempting for the actors to free-ride on the others' contribution.
} 
contribution for individualized rationing, and both symmetric and asymmetric contributions including a number of over-contributions for individualized taxation. Repeating the game fifty times allows us to observe the convergence to the predicted Nash equilibria and its speed, and the selection of equilibrium when many equilibria exist. Thus, the experimental design enables a clean comparison of four widely used policies which are normatively equivalent but may lead to much contrasted equilibria

The specificity of our paper with respect to the experimental literature on the provision of public goods is fourfold. The first specificity has to do with the nature of the good. Our game considers collective goods and not public goods, in the sense that only the victims of the disaster can share the good whereas a pure public good is non-excludable. In public good games, each subject generally benefits from a unique marginal return from the good (Davis and Holt 1993; Ledyard 1995). In our game, since only the victims of the damage share the collective good, an individual's contribution can have a null internal return and a positive external return if he does not become a victim himself. ${ }^{2}$ This design allows us to study behavior in a framework where the subjects are not assured to get a return from their contribution and to compare the contributions as a function of whether there is a guarantee to compensate the victims or not.

The second novelty of our experiment resides in the comparison of the efficiency of sanctions on voluntary contributions when various combinations of private and public funding of the collective good are used. Here, the sanction is targeted only to the victims in the case of purely private financing of the collective good (rationing), whereas it is inflicted to the entire group in the case

2 Other experiments allow a contribution to the public good to have an interior return (for the person who contributes) different from its public return (for the other members) to isolate altruism (Carter, Drainville, and Poulin 1992; Goeree, Holt, and Laury 2002). In contrast, in our experiment, when an individual decides of his contribution, he ignores whether or not he will be a victim of the damage. 
of mixed financing (taxation). Since taxation triggers an additional monetary cost, a crowdingout effect of the voluntary contributions by taxation (Bergstrom, Blume, and Varian 1986; Roberts 1987; Andreoni 1993) is less likely in our experiment.

The third novelty of our experiment is the comparison of the efficiency of uniform versus individualized mechanisms. Individualization is here related to a difference in the individuals' contribution behavior, not to a difference of their ex ante situation (in terms of endowment, Isaac and Walker, 1988, or of marginal return of the good, Chan, Mestelman, Moir, and Muller, 1999). It becomes feasible to test whether individualizing the consequences of a deficit gives the agents a sense of responsibility towards the voluntary funding of the collective good, whereas uniform treatments reduce the feeling of responsibility. ${ }^{3}$

A last specificity of our experiment lies in the non linearity of the collective good's return, which allows us to compare various treatments having a common interior optimum but different Nash equilibria. Introducing an interior equilibrium in public good games, Andreoni (1993), Sefton and Steinberg (1996), Keser (1996), Isaac and Walker (1988), Willinger and Ziegelmeyer (1999), Holt and Laury (2000) show that the subjects still over-contribute, but over-contribution is reduced as the equilibrium draws closer to the optimum. In our game the optimum is interior and similar across treatments, and we vary its distance to the equilibria. Thus, we can study how various cooperation risks, i.e. the gap between the equilibrium and the optimum, influence behavior.

The predictions of our theoretical model are confirmed by the results of the experiment. Uniform rationing is the least efficient system in terms of the contribution level in that it does not

\footnotetext{
${ }^{3}$ From a theoretical point of view, Kirchsteiger and Puppe (1997) show that a linear uniform tax-subsidy policy, where the individual tax depends solely on the sum of the other members' voluntary contributions, can implement the optimal contribution only under very strict conditions.
} 
discourage free-riding and the service is not provided to the victims. Uniform taxation does not perform much better since the collective good is provided but at an extra cost for the community, which puts a strain on efficiency. Individualized rationing enhances the sense of responsibility, but cooperation is not complete and the service is not provided in full. The most efficient institution turns out to be individualized taxation. With an average contribution in the neighborhood of the optimum, cooperation is more important and is stable over time. This mechanism confers to individuals the highest sense of responsibility towards the funding of the collective good. It cancels most of the crowding-out effect of taxes on the voluntary contributions, by protecting cooperative individuals against being exploited by the free riders.

The rest of the article is organized as follows. Section 2 presents the theoretical model. Section 3 details the experimental design. Section 4 analyzes the results. Finally, section 5 concludes and discusses the implications of these observations.

\section{THEORY}

The game consists of a two-stage collective good (insurance) game. For each of the four treatments that we consider, we identify in this section the social optimum and Nash equilibria.

Every individual decides whether to spend part of his income $Y$ on a mutual fund, which has the purpose of covering losses for randomly hit subjects.

Let $Y \equiv 100$ tokens be the income perceived by subject $i \in(1, \ldots, N)$ in a given period;

$g_{i}$ : the voluntary contribution of individual $i$ to the collective good $\left(g_{i} \geq 0\right)$;

$d_{i} /$ : the random loss suffered by individual $i$, which can only take two values: 0 or $d>0$. This loss is an i.i.d. Bernoulli variable. 
$\pi_{i}$ : the profit or net payoff of $i$ ( $\tilde{\pi}_{i}$ if the individual profit is random).

Each of the S victims may experience one disaster at most in any period of game. ${ }^{4}$ Thus, $p \equiv \frac{S}{N}$ represents the probability that any individual in a group of $N$ become a victim following $S$ draws without replacement. In our experiment, $N=12, S=4$; hence, $p=1 / 3$.

We consider successively $2 \times 2$ policies that can be implemented in case of a budget deficit: (taxation, rationing) $\mathrm{x}$ (uniform, individualized). In case total contributions exceed the total losses experienced by the victims, the surplus is burnt. ${ }^{5}$

\subsection{Uniform taxation}

The payoff function is:

$$
\pi_{i}= \begin{cases}100-g_{i}-\frac{1}{N}\left[L-\sum_{j=1}^{N} g_{j}\right]-\left[\beta+\frac{\alpha}{2 N}\left(L-\sum_{j=1}^{N} g_{j}\right)^{2}\right] & \text { if } \quad L>\sum_{j=1}^{N} g_{j} \\ 100-g_{i} & \text { if } \quad L \leq \sum_{j=1}^{N} g_{j}\end{cases}
$$

where $\alpha$ and $\beta>0$.

The individual i's final payoff is represented by the second row of Equation (1) when the budget is sufficient ex ante to cover losses in the aggregate. It is then simply obtained by subtracting $i$ 's voluntary contribution to the collective good from the period income. There is an obvious

\footnotetext{
${ }^{4}$ This hypothesis makes the number of disasters $S$ and the total amount of losses $\left(\sum_{i=1}^{N} \widetilde{d}_{i} \equiv S d=L\right)$ fixed values, thus shortening the gap between the situation of a small experimental group and what the law of large numbers would naturally achieve in a large group.

${ }^{5}$ We justify this assumption by its experimental simplicity, and for reflecting the inflationary nature of public expenditure through the principle that most taxes are not targeted, so that a local surplus will be redistributed to other public uses within the same period.
} 
incentive for each player to free ride if losses can be covered by the voluntary contributions of other players. However, irresponsible behavior tends to create a budget deficit ex ante; and, if this occurs, individual i's final payoff will be defined by the first row of Equation (1). The income net of own contribution is now diminished by the cost of financing the deficit imputed to i. The third term describes the individualized contribution to covering the deficit. The last term between brackets with $\alpha, \beta>0$ represents the extra cost of taxation. The latter is a quadratic function of the deficit because the deadweight loss of taxation is supposed to increase in the size of the deficit. Under uniform taxation, all members of the pool share the same burden irrespective of their initial contribution.

The complete coverage of victims removes any risk. The planner simply maximizes the sum of payoffs which is symmetric in all individual contributions. Hence, everybody must contribute by the same amount:

$$
g_{j} \equiv g_{i} \quad \forall j \neq i \in(1, \ldots, N)
$$

The normative payoff per capita (1) is described as follows:

$$
\pi_{i}^{*}=\left\{\begin{array}{ccc}
100-\frac{L}{N}-\left\{\beta+\frac{\alpha}{2 N}\left[L-N g_{i}\right]^{2}\right\} & \text { if } \quad g_{i}<\frac{L}{N} \\
100-g_{i} & \text { if } \quad \mathrm{g}_{\mathrm{i}} \geq \frac{L}{N}
\end{array}\right.
$$

Function $\pi_{i}^{*}$ reaches its maximum when $g_{i}=\frac{L}{N}$, and the budget is balanced ex ante. This defines the social optimum.

The Nash equilibrium is attained when each player $i$ maximizes his payoff with respect to the others' contributions. If $\bar{g}$ denotes the average contribution of all the other players, $i$ 's payoff is: 


$$
\pi_{i}=\left\{\begin{array}{lr}
100-g_{i}-\frac{1}{N}\left[L-(N-1) \bar{g}-g_{i}\right]-\left[\beta+\frac{\alpha}{2 N}\left(L-(N-1) \bar{g}-g_{i}\right)^{2}\right] & \text { if } g_{i}+(N-1) \bar{g}<L \\
100-g_{i} & \text { if } g_{i}+(N-1) \bar{g} \geq L
\end{array}\right.
$$

In the presence of a deficit, the payoff is given by the first row of Equation (3). Its maximum is reached for a null contribution if the following condition is met: $\alpha L \leq N-1$, which is the case for reasonable values of $\alpha$ and, in particular, in our experiment. By symmetry, all the players then have a null contribution in equilibrium. In the absence of a deficit, the maximum payoff is obtained for: $g_{i}=L-(N-1) \bar{g} \equiv D \geq 0$, where $D$ is the ex ante deficit before $i$ 's contribution and takes an integer value. For Nash equilibrium to exist without an ex ante deficit, we must have: $\pi_{i}(D) \geq \pi_{i}(0)$. Comparison of the first and second rows of Equation (3) yields after simplification: $\frac{\alpha}{2 N} D^{2}-\frac{N-1}{N} D+\beta>0$.

With the numerical values given to the constant parameters $\alpha$ and $\beta$ in our experiment ( $\alpha=.005, \beta=2$ ), the only admissible values are: $D=0,1,2$, that is, $N-1$ subjects almost cover total expected losses all together and the $N^{\text {th }}$ player gives almost nothing. However, such equilibria seem highly implausible and should not be selected if players have rational expectations. Indeed, they imply that a player believes that some other players have overcontributed (above $\mathrm{L} / \mathrm{N}$ ), which is not a rational expectation in our design in which any budget surplus is burnt, unless the fixed and marginal deadweight cost of a deficit grow large enough. Thus, when uniform taxation is used to finance a budget deficit, zero contribution is the likely Nash equilibrium if $\alpha L \leq N-1$. 


\subsection{Individualized taxation}

In contrast with the previous policy, the tax levied on individual $i$ for financing a budget deficit now offsets the voluntary contribution. Player i's payoff is therefore defined as follows:

$$
\pi_{i}=\left\{\begin{array}{cl}
100-g_{i}-\frac{\frac{L}{N}-g_{i}}{L-\sum_{j=1}^{N} g_{j}}\left[L-\sum_{J=1}^{N} g_{j}\right]-\left\{\beta+\frac{\alpha}{2 N}\left[L-\sum_{j=1}^{N} g_{j}\right]^{2}\right\} & \text { if } \quad L>\sum_{j=1}^{N} g_{j} \\
100-g_{i} & \text { if } \quad L \leq \sum_{j=1}^{N} g_{j}
\end{array}\right.
$$

The term between brackets with $\alpha, \beta>0$ represents the extra cost of financing the deficit. The third term describes the individualized contribution to covering the deficit.

After simplification,

$$
\pi_{i}= \begin{cases}100-\frac{L}{N}-\beta-\frac{\alpha}{2 N}\left[L-\sum_{j=1}^{N} g_{j}\right]^{2} & \text { if } \quad L>\sum_{j=1}^{N} g_{j} \\ 100-g_{i} & \text { if } \quad L \leq \sum_{j=1}^{N} g_{j}\end{cases}
$$

As in the previous case, the complete coverage of victims removes any risk. As a consequence, the normative payoff function has the same expression as in (2). Thus, the social optimum is unchanged: all subjects must equally contribute $\frac{L}{N}$ to reach a balanced budget ex ante. Although the social optimum does not depend on the nature of taxation, individualization has the effect of making the social optimum a Nash equilibrium as well. If agent $i$ is looking for the maximum payoff given the others' contributions (equal to $\bar{g}$ on average), $i$ 's payoff is expressed as:

$$
\pi_{i}=\left\{\begin{array}{c}
100-\frac{L}{N}-\beta-\frac{\alpha}{2 N}\left(L-(N-1) \bar{g}-g_{i}\right)^{2} \quad \text { if } g_{i}+(N-1) \bar{g}<L \\
100-g_{i} \quad \text { if } g_{i}+(N-1) \bar{g} \geq L
\end{array}\right.
$$


It reaches its maximum when the budget is balanced ex ante, if $D \leq L / N+\beta$, i.e. if $(N-1)$ members of the group have made on average an almost optimal contribution. One of these balanced budget-equilibria is symmetric and coincides with the social optimum. Intuitively, an individual who believes that other members have paid their share of expected total losses and knows that he will have to pay his own share anyway will prefer to do it ex ante rather than $e x$ post in order to avoid the payment of the additional cost.

There are also asymmetric equilibria with an ex ante budget deficit. In these, the individualized taxation guarantees that the more generous players will not be penalized ex post, since all players eventually will get the same profit. Furthermore, as their payoff depends on the ex ante deficit and rapidly decreases in this deficit (given the quadratic term), some players may over contribute relative to the social optimum in order to curb the deficit and the resulting efficiency cost.

\subsection{Uniform rationing}

Rationing the contributors is another way of financing a publicly-funded insurance. Now, there can be no deficit to be covered ex post because the amount of indemnities will be automatically adjusted to the sum of voluntary contributions if the latter are not high enough to cover all losses. Pool members collectively bear the risk of being only partly covered if they become victims, so that an agent's net payoff becomes uncertain even though the sum of individual losses is certain. We first consider uniform rationing of the victims: each victim's loss is limited by the sum of all contributions to the fund relative to losses. This is expressed as follows: 


$$
\tilde{\pi}_{i}= \begin{cases}100-g_{i}-\tilde{d}_{i}\left(1-\frac{\sum_{j=1}^{N} g_{j}}{L}\right) & \text { if } \sum_{\mathrm{j}=1}^{\mathrm{N}} \mathrm{g}_{\mathrm{j}}<L \\ 100-g_{i} & \text { if } \sum_{\mathrm{j}=1}^{\mathrm{N}} \mathrm{g}_{\mathrm{j}} \geq L\end{cases}
$$

The presence of an individual risk makes the definition of the social optimum problematic because the social planner must account for the players' risk attitudes. A psychologicallyfounded solution (see Lévy-Garboua et al., 2006) is to assume that the social planner behaves like an impartial judge who, by lack of knowledge of others, attributes them his own characteristics in terms of initial wealth and risk aversion. Since all members of the group enter symmetrically in this game, the social planner $i$ would choose the same contribution $g_{i}$ for all and eventually maximize his own expected utility, $E U_{i}\left(w_{i}+\tilde{\pi}_{i} *\right)$, with:

$$
\tilde{\pi}_{i}^{*}=\left\{\begin{array}{lll}
100-g_{i}-\tilde{d}_{i}\left(1-\frac{N g_{i}}{L}\right) & \text { if } \quad g_{i}<\frac{L}{N} \\
100-g_{i} & \text { if } \quad g_{i} \geq \frac{L}{N}
\end{array}\right.
$$

If the sum of contributions covers the sum of losses, all subjects are fully insured and receive a sure payoff. The optimum is then obtained for $g_{i}=\frac{L}{N}$. However, payoffs are uncertain if contributions fall short of the amount of losses. Consequently, the social planner maximizes the following expected utility:

$$
E U_{i}\left(w_{i}+\tilde{\pi}_{i}^{*}\right)=(1-p) U_{i}\left(w_{i}+100-g_{i}\right)+p U_{i}\left(w_{i}+100-g_{i}-d\left(1-\frac{N g_{i}}{L}\right)\right)
$$

where $U_{i}$ designates his concave utility function of wealth $\left(U_{i}^{\prime}>0, U_{i}^{\prime \prime}<0\right)$. It is shown in Appendix A that the social optimum still corresponds to $g_{i}=\frac{L}{N}$, as in the case of taxation. A 
remarkable feature of our definition of the social optimum is that it is robust to variations of endowed wealth and risk aversion.

To determine the Nash equilibrium, we consider that player $i$ maximizes his expected utility given the other players' contributions $\left(g_{1}, \ldots, g_{i-1}, g_{i+1}, \ldots, g_{N}\right)$. The payoff writes as:

$$
\tilde{\pi}_{i}=\left\{\begin{array}{c}
g_{i}+\sum_{j \neq i} g_{j} \\
100-g_{i}-\tilde{d}_{i}\left[1-\frac{\text { if }}{L} g_{i}+\sum_{j \neq i} g_{j}<L\right. \\
100-g_{i} \text { if } g_{i}+\sum_{j \neq i} g_{j} \geq L
\end{array}\right.
$$

If there exists a Nash equilibrium without a budget deficit, it must be $g_{i}=D$ and $\pi_{i}=100-D$. In case of a budget deficit, the random payoff is described by the first line of equation (9) and the expected utility writes as follows:

$$
\begin{aligned}
E U_{i}\left(\tilde{\pi}_{i}\right) & =(1-p) U_{i}\left(w_{i}+100-g_{i}\right)+p U_{i}\left(w_{i}+100-\frac{L}{S}+\frac{\sum_{j \neq i} g_{j}}{S}-\frac{S-1}{S} g_{i}\right) \\
& =(1-p) U_{i}\left(w_{i}+100-g_{i}\right)+p U_{i}\left(w_{i}+100-\frac{D}{S}-\frac{S-1}{S} g_{i}\right)
\end{aligned}
$$

It reaches its maximum when the player's contribution is null regardless of the other players' contributions. The null contribution represents the only equilibrium since the expected utility is then greater than the balanced budget utility $U_{i}\left(w_{i}+100-D\right)$ for all $D$.

\subsection{Individualized rationing}

The rationing is individualized by having it depend on each individual contribution to the fund relative to the contributions of the other victims. We impose here the two following 
conditions, implicitly respected by previous institutions: (i) a victim's compensation can never exceed his loss; (ii) the sum of compensations paid to the victims is always covered by the sum of contributions. This can be written as:

$$
\tilde{\pi}_{i}=100-g_{i}-\tilde{d}_{i}\left(1-c_{i}\right)
$$

where $c_{i}$ is the coverage rate of losses, lying between 0 and 1 (condition (i)). The condition (ii) imposes: $\frac{1}{S} \sum_{k=1}^{S} c_{k} \leq \frac{\sum_{j=1}^{N} g_{j}}{L}$, with $k=(1, \ldots, S)$ designating the victims within the group. When the sum of the contributions covers all the losses, each victim is fully insured and receives a certain payoff. When this sum does not cover all the losses, payoff is uncertain and the coverage of every rationed victim is proportional to his own contribution relative to that of the other victims. This writes:

$$
\begin{aligned}
& c_{i}=\min \left(1, \frac{\sum_{j=1}^{N} g_{j}}{L} \frac{g_{i}}{\frac{1}{S} \sum_{k=1}^{S} g_{k}}\right) \text { if } \sum_{j=1}^{N} g_{j}<L \\
& c_{i}=1 \quad \forall i \text { if } \sum_{j=1}^{N} g_{j} \geq L
\end{aligned}
$$

To determine the social optimum, we proceed exactly as we did in the case of uniform rationing. Thanks to the symmetry of the problem, profits take the form of Equation (7). Consequently, the social optimum is still $g_{i}^{*}=\frac{L}{N}$ for all $i=(1, \ldots, N)$, which is robust to variations in endowed wealth and risk aversion.

Consider next the Nash equilibrium of this game. If the equilibrium comprises some rationing, the coverage rate is given by the first row of Equation (11). Note, however, that the rate of 
coverage of player $i$ is irrelevant if he is not hit by the damage and that players are never better off contributing beyond what suffices to supply them with full insurance, given all the other contributions. Hence, the coverage rate given by Equation (11) can be expressed more simply as:

$$
C_{i}=\frac{g_{i}+\sum_{j \neq i} g_{j}}{g_{i}+\sum_{k \neq i} g_{k}} \frac{g_{i}}{L / S} \leq 1
$$

The individual maximizes his expected utility, which is given by:

$E U_{i}\left(\tilde{\pi}_{i}\right)=(1-p) U_{i}\left(w_{i}+100-g_{i}\right)+p U_{i}\left(w_{i}+100-g_{i}-\frac{L}{S}+\frac{g_{i}+\sum_{j \neq i} g_{j}}{g_{i}+\sum_{k \neq i} g_{k}} g_{i}\right)$,

s.t. $g_{i} \geq 0, g_{i}+\sum_{j \neq i} g_{j}<L, c_{i} \leq 1$.

Players usually hold incomplete information about the other players' preferences. Thus, it is rational for player $i$ to perceive the other players' contributions as i.i.d. draws from a given distribution and to estimate their average contribution. The occurrence of a disaster being random, this estimation must be the same for both the victims and the non-victims:

$$
\frac{\sum_{j \neq i} g_{j}}{N-1}=\frac{\sum_{k \neq i} g_{k}}{S-1}=\bar{g}_{-i}
$$

By reporting this estimation of the average contribution in Equation (13), we get:

$$
E U_{i}\left(\tilde{\pi}_{i}\right)=(1-p) U_{i}\left(w_{i}+100-g_{i}\right)+p U_{i}\left(w_{i}+100-g_{i}-\frac{L}{S}+\frac{g_{i}+(N-1) \bar{g}_{-i}}{g_{i}+(S-1) \bar{g}_{-i}} g_{i}\right)
$$

The Nash equilibrium necessarily comprises rationing if $\bar{g}_{-i} \leq L / N$, which is a rational expectation (see proof of proposition 1 in Appendix A). ${ }^{6}$ We can further characterize this equilibrium by showing that the players' contribution is positive (see proof of proposition 2 in

\footnotetext{
${ }^{6}$ The reverse condition, $\bar{g}_{-i}>L / N$, implies an over-contribution of other players on average, which is not a rational expectation if over insurance is prohibited.
} 
Appendix A). The interior equilibrium obtained under individualized rationing contrasts with the corner solution of no contribution that characterized uniform rationing.

Table 1 summarizes the theoretical solutions for each institution.

\section{[Table 1 about here]}

Only does the individualized taxation institution lead to a solution where the symmetric Nash equilibrium coincides with the social optimum. In contrast, the Nash equilibrium diverges radically from the social optimum under uniform taxation or rationing, and less sharply under individualized rationing. Therefore, from a theoretical perspective, individualized taxation is likely to constitute the best performing institution. It should be noted that, if the player maximizes the discounted profit over $T$ periods, the solutions of the four models (social optimum and Nash equilibrium) do not change thanks to the additive separability.

\section{THE EXPERIMENTAL DESIGN}

Our $2 \times 2$ experiment consists of four treatments corresponding to the four institutions modeled in the theoretical section.

Twelve participants form a group $(N=12)$. Each participant is given an initial endowment of 100 tokens. $^{7}$ Everyone can contribute to a common pool that serves to compensate the victims of a disaster who are fully deprived of their initial endowment. The individual contribution is a number of tokens chosen between 0 and $100\left(g_{i} \in[0,100]\right)$. Four of the 12 group members are then randomly hit by the disaster $(S=4)$ so that the total loss is exactly 400 tokens $(L=400)$. When

\footnotetext{
${ }^{7}$ At the beginning of the first period, to avoid the possibility of negative earnings, each participant was given an endowment of 110 tokens. This does not influence the theoretical predictions.
} 
the latter is fully and equally covered by all participants, all contributions amount to 33 or 34 tokens $^{8}$. This corresponds to the optimum in the four treatments. The deadweight loss parameters of the deficit made up by taxation are $\alpha=0.005$ and $\beta=2$. The equilibrium is to contribute nothing in the two uniform treatments. In the individualized treatments, the taxation policy leads to a symmetric equilibrium with a contribution of 33-34 and asymmetric equilibria with a number of over-contributions; and the rationing policy leads to an interior equilibrium with effective rationing and contributions spreading between 1 and 32. Each session consists of 50 periods, allowing us to observe long run contribution dynamics.

We have conducted 6 experimental sessions per treatment, for a total of 24 sessions of 12 participants each. In order to capture the possible role of cultural differences, half of the sessions for each treatment were run in Montréal (Canada), and half in Lyon (France), on the same dates. ${ }^{9}$ In total, the experiment summoned 288 French-speaking participants, mostly students. It was programmed with the REGATE software (Zeiliger, 2000).

Once all the participants were present, each one randomly drew a ticket with a computer name out of an envelope. After distributing the instructions and reading them aloud, the participants' questions were privately answered and a questionnaire was used to check that all instructions had been well understood. ${ }^{10}$ The latter were written in neutral terms. The average duration of sessions was an hour and a half including the payment of participants that was done in private in

${ }_{8} \frac{L}{N}=33.33$ must be converted in an integer number of tokens.

${ }^{9}$ The Montreal sessions were conducted in the BUL-CIRANO lab (Center for Interuniversity Research and Analysis on Organizations) and the Lyon sessions at GATE (Groupe d'Analyse et de Théorie Économique).

${ }^{10}$ The instructions for two of the treatments are presented in Appendix B. The instructions for the other treatments are available upon request to the authors. 
a separate room. The conversion rate was 300 tokens $=1.55$ Canadian Dollar $=1$ Euro. The average earnings were 35 Canadian Dollars or 23 Euros.

Moreover, the participants had a choice between getting a show-up fee of 5 Dollars (2 Euros) and participating in a lottery in which they had equal chances of winning either 11 Dollars (5 Euros) or 0 . The participants who had chosen the show-up fee were tentatively considered as being more risk averse. They tossed a coin at the end of the session to determine their extra earnings.

\section{THE RESULTS}

After a presentation of the main descriptive statistics, we successively analyze the contribution behavior, the heterogeneity of individual strategies, and the associated earnings.

\subsection{Summary statistics}

The first observation is striking but not really surprising: voluntary contributions are never sufficient to cover aggregate losses in the first stage, except for the individualized taxation treatment where a surplus was observed in $13 \%$ of the periods. Indeed, the frequency of socially optimal individual contributions is small: only $1 \%$ in the uniform rationing treatment, $4 \%$ in both the individualized rationing and the uniform taxation treatments, and a peak of $10 \%$ in the individualized taxation treatment. In addition, this frequency declines over time in three of the four treatments. The exception is for individualized taxation where the symmetric equilibrium and the optimum overlap: the frequency of socially optimal contributions then rises from $7 \%$ in the first ten periods to $12 \%$ on average in the last ten periods.

As a crude approximation, the spectrum of Nash equilibria is reflected in the spread of average contributions across treatments. Participants gave 27.16 tokens on average (S.D. $=22.55)$ under 
individualized taxation and 15.74 tokens (S.D. =17.77) under individualized rationing, in conformity with the prediction of interior equilibria for individualized policies and of symmetric or almost symmetric equilibria for individualized taxation. They only contributed 10.50 tokens (S.D. $=15.26)$ under uniform taxation and 8.77 tokens (S.D. $=16.55)$ under uniform rationing for which the predicted equilibrium is a null contribution. Under uniform policies, the frequency of equilibrium, i.e. null, contributions is higher in the uniform rationing treatment $(53 \%)$ than in the uniform taxation treatment $(38 \%)$. In contrast, null contributions are relatively rare in individualized treatments, where they diverge from equilibrium $(14 \%$ in the individualized taxation treatment and $28 \%$ in the individualized rationing treatment). Figure 1 displays the evolution of the average contributions over time for each treatment.

[Figure 1 about here]

Figure 1 shows a strong proximity of the average contributions in the first period across treatments, with the exception of uniform rationing for which it is right away inferior. The average contribution in the first period is about two thirds of the social optimum. This strong regularity suggests that participants do not immediately anticipate the final equilibrium and follow a prior norm in the absence of information on the others' behavior. Behavior evolves however differently across treatments as the individuals get gradually informed of others' behavior. Individualized treatments stabilize the average contributions at a high level, whereas uniform treatments lead to a decline of contributions at the same speed. Therefore, the common behavior that we observed in the first period cannot be interpreted as a signal of the players' willingness to cooperate. This gives further credit to the norm's adherence interpretation of initial behavior. In complement to these descriptive statistics, Table 2 analyzes the influence of time on individual contributions in the long run by estimating an OLS model for each treatment. 
[Table 2 about here]

The econometric analysis displayed in Table 2 confirms that, with the exception of the individualized taxation treatment, the average contributions to the collective good decrease with time. If one estimates the asymptotic convergence in the treatments where the Nash equilibrium is to contribute nothing, the players should reach the equilibrium at the $63^{\text {rd }}$ period. In contrast, over all 50 periods, the average contribution in the individualized taxation treatment is stable and is only 6 units less than the optimum.

Since the optimum is the same across treatments, behavior seems to be mainly guided by the equilibrium of each game. It is also very clear that individualized taxation dominates all other policies and that the individualization of sanctions to under-provision reduces the prevalence and development of free riding that is much more apparent in the uniform treatments. Although the optimum coincides with one of the symmetric equilibria in this taxation treatment, the optimum is however still not reached. This kind of situation has been observed before in the work of Saijo and Nakamura (1995).

\subsection{Determinants of the contribution behavior}

In order to analyze contribution behavior, we proceed with a two-step estimation. ${ }^{11} \mathrm{We}$ explain first the decision to contribute at all, and next the choice of a positive contribution conditional on the decision to contribute. The first decision is studied by means of a panel Probit model; and the conditional amount spent on the collective good is estimated with a Feasible Generalized Least Squares model corrected from the selectivity bias. Table 3 displays the results of these regressions.

\footnotetext{
${ }^{11}$ A Tobit model of type 2 (or generalized Tobit) would be ideal for a one-step estimation, but is not very user-friendly with panel data.
} 
[Table 3 about here]

The impact of time on contributions appears in the first row of table 3. In the uniform taxation treatment, both a higher number of zero contributions and a lower level of positive contributions explain the decline in the average contribution over time. In the uniform rationing and the individual taxation treatments, the probability to contribute decreases over time. In the individualized rationing treatment, the decline is due to a lower level of positive contribution.

After controlling for the time trend and demographic variables ${ }^{12}$ in the regressions, we introduce a number of lagged exogenous variables and individual controls. The lagged variables are intended to capture the process of convergence to equilibrium and temporary deviations from the time trend.

The sum of the other group members' contributions in the previous period controls for conditional cooperation. For the sole individualized taxation treatment, we add a variable interacting the others' contribution in the previous period with a dummy variable equal to 1 if the fund exhibits a deficit in that period; this variable is not included in the other regressions since the fund is always in deficit in the other treatments. Our results demonstrate that conditional cooperation essentially concerns taxation policies. A simple reason why it does not show up in the rationing treatments is that luck and risk taking behavior interfere with cooperative behavior to determine the net gains of any participant relative to the others. In the uniform taxation treatment, conditional cooperation is only visible on the decision to contribute at all. Indeed, since a uniform contribution to the budget deficit in the second stage does not level off previous

\footnotetext{
${ }^{12}$ The individual controls include age, gender, student or worker status, education level, mathematical studies, past participation in an experiment, and location of the session (see descriptive statistics in Appendix C). The lottery choice is taken into account as a risk aversion index. The demographic variables play no systematic role in the taxation treatments and few intervene in the rationing treatments.
} 
disparities among contributors and the Nash equilibrium is a null contribution in this case, cooperators soon understand that their own efforts to cooperate are undermined by free riders to the exclusive benefit of the latter.

The process is different in the individualized taxation treatment since many participants cooperate to some extent. Thus, conditional cooperation is now visible on the choice of how much to contribute. The coefficient of the interaction variable formed with the others' contribution in the previous period when the budget was in deficit is significantly negative. This means that, when the fund is in deficit in the previous period, the reaction of participants to a perceived low contribution of others is to offer a high contribution to avoid the penalty associated with a deficit; whereas if the contribution of others is high, participants offer a low contribution to avoid making a surplus that would be burnt.

Two lagged variables describe the player's previous exposure to losses, namely the occurrence of a disaster in the last period and a measure of persistent bad luck in past periods. Persistent bad luck is captured by the difference between the number of disasters suffered by a participant during the elapsed periods and the expected number of disasters given the objective probability of a disaster. Since taxation guarantees the full compensation of losses and eliminates uncertainty, it is not surprising that the event of a disaster in the last period does not have a significant effect on contributions in the taxation treatments. In sharp contrast, the occurrence of a disaster diminishes the probability of a positive contribution in the next period in the rationing treatments. Since it is common knowledge that periods are independent, this may reveal a gambler's fallacy, in which 
the unlucky individual underestimates the chances that his bad luck persists in the future. ${ }^{13}$ The interpretation of the persistent bad luck variable's effect is more complex. In the treatments with rationing, the coefficients are positive and significant in the individualized treatment that evokes the "hot hand fallacy". Individuals seem to think that, if they have been lucky or unlucky for some time, they will continue to be so in the future because it reflects their nature, and so they must take proper risk coverage. Such behavior runs counter the gambler's fallacy hypothesis. In the taxation treatments, however, the estimated coefficients of this variable are significantly negative: persistent bad luck diminishes the probability of a positive contribution. This cannot be explained by any "cognitive" bias like the gambler's fallacy or the hot hand fallacy because taxation policies eliminate individual risk. Our preferred interpretation is that an "excessive" accumulation of bad luck triggers an emotional rejection of cooperation, just like an angry responder would reject a low offer in the ultimatum game.

Overall, individual behavior tends to gradually diverge from the optimum and converge toward the Nash equilibrium values as players are informed of the behavior of others. In the short run, players move around this trend following their good or bad luck.

\subsection{Heterogeneity of Strategies}

Recent experimental literature has emphasized the heterogeneity of preferences and its impact on behavior in public goods games (see for example Burlando and Guala, 2005). In our game, it can also be suspected that all participants do not adopt the same strategies in each treatment. Thus, homogeneous groups of participants and strategies have been separated by a

\footnotetext{
${ }^{13}$ An alternative explanation is that participants become more risk seeking after experiencing one loss, as they envision the possibility of an accumulation of losses in the future, and try to regain the experienced loss by taking risk and saving on contributions.
} 
cluster analysis based on three discriminating variables: frequency of positive contributions, average and standard deviation of the contributions. A small number of non-null contributions, a low average and low standard deviation of contributions should indicate a non-cooperative strategy, whereas a high frequency of non-null contributions suggests a cooperative strategy. The standard deviation of the contributions identifies the variety of strategies.

Although the hierarchical Ward method identifies 8 to 10 clusters, two clusters for all treatments is enough to oppose very different strategies, since the other strategies are close to the second cluster. ${ }^{14}$ Table 4 characterizes these strategies for each treatment.

\section{[Table 4 about here]}

In Table 4, cluster 2 corresponds to a non-cooperative strategy: a small number of non-null contributions, a low average and standard deviation of contribution. In cluster 1, the number of non-null contributions and the average contribution are clearly higher, while still remaining much smaller than the optimum. The standard deviation of contributions is large, suggesting a hesitant strategy, most likely related to the reactions to the other group members' behavior. Excluding the individualized taxation treatment, between $55 \%$ and $62 \%$ of the participants to the other treatments retain a relatively cooperative strategy compared to the other participants. On the other hand, in the treatment with individualized taxation, $43 \%$ of the participants use a rather cooperative strategy, close to the optimum. For that treatment, the second cluster shows

\footnotetext{
${ }^{14}$ Insofar we want to identify the most contrasting groups of behavior, we have used a difference criterion as an aggregation mean. The maximum link method (the distance between two groups is given by the distances of the furthest object of each group) and the Ward method (minimizing the intra-group variance) are best fitting. Since the Ward method tends to produce smaller groups, we have favored this method, that is, the minimization of the squared sum of the errors (the squared Euclidian distance $\left.\sum_{k=1}^{p}\left(x_{k i}-x_{k j}\right)^{2}\right)$. Regarding the choice of the number of partitions, insofar we want to preserve the greatest differences between groups, we examine the decreasing curve of the distances between the merged partitions in each stage. This curve must diminish in a monotonous fashion as the near partitions are merged in each stage. If a net difference is observed in the course of iteration, it is not reasonable to group other partitions.
} 
participants with a high number of non-null contributions, but with an average halfway to the optimum.

A non-parametric analysis confirms the existence of differences between the individualized taxation treatment and the other treatments for the relatively cooperative cluster. In addition, the null hypothesis is often rejected in comparing the treatments that do not involve individualized taxation. In contrast, no difference can be found between treatments for the non cooperative cluster with only one exception ${ }^{15}$.

\subsection{Winning and Losing Strategies}

The participants earned 48.26 tokens on average (S.D.=15.88) in the uniform taxation treatment, 66.55 tokens $(\mathrm{S} . \mathrm{D} .=39.01)$ in the uniform rationing treatment, 66.57 tokens (S.D. $=32.85)$ in the individualized rationing treatment, and 61.69 tokens $($ S.D. $=9.79)$ in the individualized taxation treatment. Thus, average earnings are lowest in the uniform taxation treatment (see Appendix C), due to the extra cost of an ex ante deficit. The variance of earnings is minimized by individualized taxation since most contributions are then concentrated around the optimum. Table 5 depicts regressions by Ordinary Least Squares on the participants' earnings.

\section{[Table 5 about here]}

Table 5 shows that, naturally, the number of disasters considerably affects the earnings in rationing treatments, since losses are not fully insured. Frequent free-riding, as measured by the number of null contributions by an individual, is a winning strategy in uniform treatments, since it allows transferring the cost of the deficit compensation to others. Conversely, a sustained

\footnotetext{
${ }^{15}$ The exception was found in comparing average contributions and standard deviations between uniform taxation and individualized rationing.
} 
cooperation, as measured by the number of optimal contributions by an individual, is rather self defeating, except for the individualized taxation treatment where the coefficient associated with this variable is positive, but not significant. This effect is very pronounced in the uniform taxation treatment. Repeatedly choosing to contribute the optimum in this context may seem strange but it might reflect leadership by example, strict adherence to the norm, or confusion.

\section{CONCLUSION}

Most developed countries are facing recurrent difficulties to finance high quality health insurance regimes and other collective needs. A fraction of the taxes collected to fund these regimes is acceptable, therefore voluntary, but the deficit of these regimes leads to a debate on what the most relevant mode of financing is. Is it more efficient from an economic point of view to ration the access to these services in case of a deficit, or is it better to levy additional taxes?

Our experimental analysis participates to this discussion by analyzing under what conditions will economic agents cooperate to the point where the collective good can be provided efficiently to all of the members in need. Four alternative institutions are compared: uniform taxation, individualized taxation, uniform rationing and individualized rationing. In all cases, unlike most public goods games, the individual's investment in the collective good can have a null marginal return if he is not the victim of a disaster. If one keeps in mind the comparison with the health insurance, it means that individuals contribute even though they are in good health. The social dilemma is therefore enhanced in our environment. The theoretical modeling allows us to identify an interior social optimum common to all the treatments, and Nash equilibria located either in corner (in the case of uniform rationing and taxation), or possibly at the same level as the optimum (in the case of individualized taxation), or at an intermediate level (in the case of 
individualized rationing). This game thus allows us to test the influence of these various institutions on the individual decisions to contribute, and to measure the relative efficiency of taxation and rationing in handling the deficits. By varying the risk associated with cooperation (i.e. the distance between the equilibrium and the optimum), it also permits to analyze whether behavior is more influenced by the optimum or by the equilibrium.

With respect to the relative efficiency of the various institutions, the experimental results are compliant with the theoretical model. Uniform rationing appears to be the worst system. The service is not supplied in full since each individual is encouraged to flee cooperation. Uniform taxation, while encouraging free-riding just as much, is not much more efficient since it imposes upon the community an excess burden and leads to the lowest average earnings. On the contrary, individualization increases the contribution levels. With individualized rationing, the collective good is not always supplied in full and the more unlucky an individual, the lower his earnings. Individualized taxation is the best institution since it increases drastically the level of contribution. In other words, it gives individuals a sense of responsibility in the provision of the collective good. Without always attaining the optimum, the average contribution is close to the optimum and stable: individuals contribute to avoid taxation.

We complement Andreoni's (1993) conclusion that taxation (exogenous in his study) encourages cooperation- by ensuring that the contributors' generosity is not exploited by others. Indeed, we show that, when taxation is endogenous, his conclusion is only true for individualized taxation. However, it is worth noting that, even when taxation is individualized, the optimum is reached hardly more than $10 \%$ of the time and voluntary contributions remain slightly inferior to the optimum on average. This could be the consequence of our assumption that budget surpluses are not credited to the next period. It could also denote a very slight crowding-out effect of the 
taxation on the voluntary contribution, or some confusion about the consequences of taxation in terms of tax overload from some subjects.

Our policy conclusions should be taken with caution, as they might be sensitive to factors that were kept constant in our experiment like size and probability of loss, use of budget surplus and loading factor. It is however likely that our main qualitative conclusions regarding the superiority of individualized over uniform treatments and of taxation over rationing remain valid for plausible values of the parameters. The results regarding how an institution can improve the sense of individual responsibility suggest the instigation of user fees or deductibles: individuals participate to the funding of the program according to their needs. Although all have the same probability to benefit from the program, the tax funding ensures its existence, while the user fees mark out those who effectively use and abuse the collective good. 


\section{REFERENCES}

Andreoni J. (1993). "An Experimental Test of the Public Goods Crowding-out Hypothesis." American Economic Review, 83(5), 1317-27.

Bergstrom T. C.; L.E. Blume, and H.R. Varian (1986). "On the Private Provision of Public Goods." Journal of Public Economics, 29, 25-49.

Burlando, R.M., and F. Guala (2005). "Heterogenous Agents in Public Goods Experiments." Experimental Economics 8, 35-54.

Carter J.R., B.J. Drainville, and R.P. Poulin (1992). "A Test for Rational Altruism in a PublicGoods Experiment." Unpublished paper, College of Holy Cross.

Chan K.S., S. Mestelman,R. Moir, and R.A. Muller (1999). "Heterogeneity and the Voluntary Provision of Public Goods." Experimental Economics, 3, 5-30.

Davis D.D. and C.A. Holt (1993). Experimental Economics. Princeton: Princeton University Press.

Dawes R.M. and R.H. Thaler (1988). "Anomalies: Cooperation." Journal of Economic Perspectives, 2, 187-97.

Goeree J.K., C.H. Holt and S.K. Laury (2002). "Private Costs and Public Benefits: Unraveling the Effects of Altruism and Noisy Behavior." Journal of Public Economics, 83(2), 255-76.

Holt C.A. and S.K. Laury (2000). "Theoretical Explanations of Treatment Effects in Voluntary Contributions Games," C. R. Plott and V. Smith, Handbook of Experimental Economic Results. New York: Elsevier,

Isaac R.M. and J.M. Walker (1988). "Communication and Free-Riding Behavior: The Voluntary Contribution Mechanism." Economic Inquiry, 26, 585-608.

Keser C. (1996). "Voluntary Contributions to a Public Good When Partial Contribution Is a Dominant Strategy." Economics Letters, 50, 359-66.

Kirchsteiger G., and C. Puppe (1997). "On the Possibility of Efficient Private Provision of Public Goods through Government Subsidies." Journal of Public Economics, 66, 489-504.

Ledyard J.O. (1995). "Public Goods: A Survey of Experimental Research," J. H. Kagel and A. E. Roth, Handbook of Experimental Economics. Princeton: Princeton University Press,

Olson M. (1965). The Logic of Collective Action: Public Goods and the Theory of Groups. Cambridge: Cambridge University Press.

Ostrom E. (1990). Governing the Commons: The Evolution of Institutions for Collective Action. Cambridge: Cambridge University Press.

Roberts, R. D. (1987). "Financing Public Goods." Journal of Political Economy, 95(2), 420-37.

Saijo T., and H. Nakamura (1995). "The "Spite" Dilemma in Voluntary Contribution Mechanism Experiments", Journal of Conflict Resolution, vol.39, n³, pp.535-560.

Sefton M., and R. Steinberg (1996). "Reward Structures in Public Good Experiments." Journal of Public Economics, 61, 263-87.

Willinger M., and A. Ziegelmeyer (1999). "Framing and Cooperation in Public Good Games: An Experiment with an Interior Solution." Economics Letters, 65(3), 323-28.

Zeiliger, R. (2000). A Presentation of Regate, Internet Based Software for Experimental Economics. http://www.gate.cnrs.fr/ zeiliger/regate/RegateIntro.ppt., GATE. 


\section{TABLES}

Table 1. Theoretical solutions

\begin{tabular}{lcc}
\hline$g_{i}$ & Social Optimum & Nash Equilibrium \\
\hline Uniform Taxation & $\frac{L}{N}$ & 0 (if $\alpha L \leq N-1)$ \\
Individualized Taxation & $\frac{L}{N}$ & $\begin{array}{c}\text { Almost optimal contribution and } \\
\text { moderate budget deficit with } \\
\text { mixture of over and under } \\
\text { contributions }\end{array}$ \\
Uniform Rationing & $\frac{L}{N}$ & 0 \\
Individualized Rationing & $\frac{L}{N}$ & Interior: $0<g_{i}<\frac{L}{N}$ \\
\hline
\end{tabular}

Table 2. Average contributions by period by treatment

\begin{tabular}{|c|c|c|c|c|c|c|c|c|}
\hline & \multicolumn{2}{|c|}{ Uniform Taxation } & \multicolumn{2}{|c|}{ Uniform Rationing } & \multicolumn{4}{|c|}{ Individualized Taxation Individualized Rationing } \\
\hline & coeff. & t-stat & Coeff. & t-stat & coeff. & t-stat & coeff. & t-stat \\
\hline Period & -0.276 & -20.45 & -0.207 & -12.94 & -0.014 & -0.70 & -0.100 & -5.92 \\
\hline Constant & 17.543 & 44.37 & 14.055 & 29.96 & 27.520 & 47.40 & 18.282 & 36.93 \\
\hline $\bar{R}^{2}$ & \multicolumn{2}{|c|}{0.895} & \multicolumn{2}{|c|}{0.773} & \multicolumn{2}{|c|}{-0.010} & \multicolumn{2}{|c|}{0.410} \\
\hline
\end{tabular}

Note: In the OLS estimations, we have 50 observations per treatment 
Table 3. Probability and determinants of the positive contributions by treatment (periods 2 to 50)

\begin{tabular}{|c|c|c|c|c|c|c|c|c|c|c|c|c|c|c|c|c|}
\hline \multirow{3}{*}{$\begin{array}{l}\text { Treatment } \\
\text { Variable }\end{array}$} & \multicolumn{4}{|c|}{ Uniform Taxation } & \multicolumn{4}{|c|}{ Uniform Rationing } & \multicolumn{4}{|c|}{ Individualized Taxation } & \multicolumn{4}{|c|}{ Individualized Rationing } \\
\hline & \multicolumn{2}{|c|}{$\begin{array}{l}\text { Random effects } \\
\text { probit model }\end{array}$} & \multicolumn{2}{|c|}{ FGLS panel } & \multicolumn{2}{|c|}{$\begin{array}{l}\text { Random effects } \\
\text { probit model }\end{array}$} & \multicolumn{2}{|c|}{ FGLS panel } & \multicolumn{2}{|c|}{$\begin{array}{l}\text { Random effects } \\
\text { probit model }\end{array}$} & \multicolumn{2}{|c|}{ FGLS panel } & \multicolumn{2}{|c|}{$\begin{array}{l}\text { Random effects } \\
\text { probit model }\end{array}$} & \multicolumn{2}{|c|}{ FGLS panel } \\
\hline & Coeff. & t-stat. & Coeff. & t-stat. & Coeff. & t-stat. & Coeff. & t-stat. & Coeff. & t-stat. & Coeff. & t-stat. & Coeff. & t-stat. & Coeff. & t-stat. \\
\hline Period & -0.015 & -6.948 & -0.415 & -7.579 & -0.022 & -10.806 & -0.095 & -0.767 & -0.007 & -5.078 & 0.012 & 0.372 & 0.0017 & 1.389 & -0.134 & -6.646 \\
\hline Others' contribution in $\mathrm{t}-1$ & 0.151 & 4.572 & 0.588 & 1.058 & 0.026 & 0.556 & -0.827 & -1.572 & -0.046 & -0.835 & -0.896 & -1.566 & 0.011 & 0.318 & -0.108 & -0.328 \\
\hline $\begin{array}{l}\text { Others' contribution in t- } 1 \text { * } \\
\text { ex ante deficit in } t-1\end{array}$ & & & & & & & & & 0.065 & 0.748 & -1.379 & -1.828 & & & & \\
\hline Disaster in $\mathrm{t}-1$ & -0.016 & -0.265 & 0.155 & 0.255 & -0.348 & -7.248 & 4.191 & 2.027 & -0.110 & -1.335 & 0.407 & 0.537 & -0.5099 & -10.336 & -3.243 & -3.235 \\
\hline $\begin{array}{l}\text { Disasters minus anticipated } \\
\text { disasters }\end{array}$ & -0.032 & -1.805 & -0.395 & -1.970 & 0.030 & 1.499 & 0.288 & 0.920 & -0.030 & -2.757 & 0.073 & 0.316 & 0.018 & 2.001 & 0.600 & 3.211 \\
\hline Age & 0.004 & 0.303 & 0.338 & 1.492 & -0.042 & -3.240 & 0.879 & 2.157 & 0.023 & 1.620 & -0.174 & -0.603 & -0.029 & -2.771 & -0.021 & -0.066 \\
\hline Gender $($ Males $=1)$ & 0.393 & 4.164 & 0.650 & 0.249 & -0.414 & -3.481 & 7.344 & 1.890 & -0.818 & -4.873 & 3.667 & 0.928 & -1.640 & -13.049 & -1.025 & -0.294 \\
\hline Experience & 0.964 & 6.075 & 7.956 & 1.631 & -0.357 & -1.577 & -11.516 & -2.514 & 0.098 & 0.493 & 3.154 & 1.035 & 0.305 & 3.487 & -0.595 & -0.197 \\
\hline Lottery & 0.076 & 0.841 & 1.592 & 0.697 & 0.314 & 2.968 & -6.952 & -1.983 & 0.170 & 1.088 & 4.816 & 1.624 & -0.186 & -2.151 & 0.514 & 0.189 \\
\hline $\begin{array}{l}\text { Student (Reference : } \\
\text { worker and unemployed) }\end{array}$ & -0.802 & -2.674 & -5.088 & -1.208 & 0.129 & 0.602 & -8.111 & -1.485 & 0.672 & 2.011 & 6.935 & 1.159 & -0.926 & -1.418 & -4.141 & -0.846 \\
\hline Graduate & -0.885 & -5.171 & -6.058 & -1.504 & 0.750 & 6.218 & -7.001 & -1.198 & 0.569 & 2.745 & -5.574 & -1.266 & 0.622 & 3.178 & -9.078 & -2.444 \\
\hline Mathematical training & 0.109 & 1.011 & 2.206 & 0.779 & -0.185 & -1.510 & 2.645 & 0.659 & 0.085 & 0.318 & -0.694 & -0.191 & -0.460 & -2.808 & 2.515 & 0.702 \\
\hline $\begin{array}{l}\text { Montreal (Reference : } \\
\text { Lyon) }\end{array}$ & 0.266 & 2.505 & 3.285 & 1.377 & 0.525 & 4.076 & -8.416 & -1.560 & 0.273 & 1.411 & 3.631 & 1.142 & 0.916 & 7.464 & 9.314 & 2.783 \\
\hline Constant & 0.393 & 0.857 & 4.840 & 0.524 & 1.418 & 3.564 & 32.027 & 3.158 & 1.198 & 1.954 & 21.679 & 1.775 & 3.692 & 4.856 & 25.123 & 2.342 \\
\hline$\rho$ & 0.575 & 19.180 & & & 0.625 & 26.639 & & & 0.580 & 10.416 & & & 0.621 & 22.280 & & \\
\hline IMR & & & 12.297 & 1.976 & & & -14.441 & -1.673 & & & -30.104 & -0.980 & & & 3.186 & 0.730 \\
\hline $\mathrm{R}^{2}$ & \multicolumn{4}{|c|}{0.093} & & & \multicolumn{2}{|c|}{0.178} & \multicolumn{4}{|c|}{0.080} & & & \multicolumn{2}{|c|}{0.078} \\
\hline Observations & \multicolumn{2}{|c|}{3528} & \multicolumn{2}{|c|}{2187} & \multicolumn{2}{|c|}{3528} & \multicolumn{2}{|c|}{1655} & \multicolumn{2}{|c|}{3528} & \multicolumn{2}{|c|}{3030} & \multicolumn{2}{|c|}{3528} & \multicolumn{2}{|c|}{2537} \\
\hline \multicolumn{17}{|l|}{ Value of the likelihood: } \\
\hline $\mathrm{V}:$ constrained & \multicolumn{2}{|c|}{-2342.99} & & & \multicolumn{2}{|c|}{-2438.68} & & & & & & & & & & \\
\hline $\mathrm{V}$ : probit & & & & & & & & & & & & & & & & \\
\hline $\mathrm{V}$ : probit panel & & & & & & & & & & & & & & & & \\
\hline
\end{tabular}


Table 4. Cluster analysis of strategies

\begin{tabular}{|c|c|c|c|c|c|c|c|c|}
\hline \multirow{2}{*}{$\begin{array}{l}\text { Treatment } \\
\text { Clusters }\end{array}$} & \multicolumn{2}{|c|}{ Uniform Taxation } & \multicolumn{2}{|c|}{ Uniform Rationing } & \multicolumn{2}{|c|}{ Individualized Taxation } & \multicolumn{2}{|c|}{ Individualized Rationing } \\
\hline & Cluster 1 & Cluster 2 & Cluster 1 & Cluster 2 & Cluster 1 & Cluster 2 & Cluster 1 & Cluster 2 \\
\hline \multicolumn{9}{|c|}{ Frequency of non-null contributions } \\
\hline Average $\%$ & 42.333 & 15.667 & 37.051 & 7.939 & 48.742 & 38.537 & 44.622 & 21.815 \\
\hline Standard Deviation & 6.566 & 8.049 & 10.252 & 6.364 & 1.999 & 11.809 & 6.847 & 11.139 \\
\hline \multicolumn{9}{|l|}{ Average of the contributions } \\
\hline Average number of tokens & 14.517 & 4.889 & 14.177 & 2.379 & 40.163 & 17.335 & 20.828 & 7.235 \\
\hline Standard Deviation & 9.289 & 3.403 & 11.504 & 2.475 & 10.304 & 8.396 & 10.046 & 4.954 \\
\hline \multicolumn{9}{|c|}{$\begin{array}{l}\text { Average of the standard deviations } \\
\text { of the contributions }\end{array}$} \\
\hline Average & 12.196 & 8.564 & 13.843 & 5.558 & 17.559 & 14.246 & 13.609 & 9.769 \\
\hline Standard Deviation & 7.241 & 5.600 & 8.637 & 5.377 & 8.015 & 7.148 & 8.735 & 4.686 \\
\hline Number of observations & 42 & 30 & 39 & 33 & 31 & 41 & 45 & 27 \\
\hline
\end{tabular}


Table 5. Participants' earnings

\begin{tabular}{|c|c|c|c|c|c|c|c|c|}
\hline \multirow{2}{*}{$\begin{array}{l}\text { Treatment } \\
\text { Variable }\end{array}$} & \multicolumn{2}{|c|}{ Uniform Taxation } & \multicolumn{2}{|c|}{ Uniform Rationing } & \multicolumn{2}{|c|}{$\begin{array}{l}\text { Individualized } \\
\text { Taxation }\end{array}$} & \multicolumn{2}{|c|}{$\begin{array}{l}\text { Individualized } \\
\text { Rationing }\end{array}$} \\
\hline & coeff. & t-stat & coeff. & t-stat & coeff. & t-stat & coeff. & t-stat \\
\hline Number of disasters & -3.152 & -0.22 & -71.834 & -4.54 & 6.287 & 1.48 & -59.900 & -6.46 \\
\hline Contribution in the first period & -4.593 & -1.23 & -10.111 & -3.00 & -1.972 & -2.37 & -6.281 & -3.25 \\
\hline $\begin{array}{l}\text { Number of choices of a null } \\
\text { contribution }\end{array}$ & 10.904 & 2.79 & 10.989 & 3.27 & 3.026 & 2.04 & -1.173 & -0.42 \\
\hline $\begin{array}{l}\text { Number of choices of an optimum } \\
\text { contribution }\end{array}$ & -15.148 & -2.05 & -23.300 & -1.43 & 1.594 & 0.81 & -8.190 & -2.02 \\
\hline Age & 6.011 & 0.53 & -6.409 & -0.58 & -0.472 & -0.17 & -6.567 & -0.81 \\
\hline Gender & 72.459 & 0.65 & -151.729 & -1.52 & -1.684 & -0.06 & 26.273 & 0.33 \\
\hline Experience & 155.834 & 0.97 & 579.577 & 4.15 & 30.688 & 1.05 & -2.013 & -0.03 \\
\hline Lottery & -23.861 & -0.22 & -50.835 & -0.54 & -62.013 & -2.21 & -10.086 & -0.14 \\
\hline $\begin{array}{l}\text { Student (Reference : worker and } \\
\text { unemployed) }\end{array}$ & -103.33 & -0.53 & -116.153 & -0.60 & -70.056 & -1.19 & 137.124 & 1.05 \\
\hline Graduated student & -40.267 & -0.25 & 104.788 & 0.74 & 35.020 & 0.87 & 129.958 & 1.34 \\
\hline Mathematical Training & 3.679 & 0.03 & -44.640 & -0.37 & 0.592 & 0.02 & -9.160 & -0.10 \\
\hline Montreal (Ref. : Lyon) & 83.820 & 0.75 & 277.587 & 2.17 & 30.309 & 1.02 & -21.596 & -0.28 \\
\hline Constant & 2338.854 & 5.00 & 4400.394 & 9.35 & 3276.084 & 21.57 & 4723.608 & 15.84 \\
\hline $\bar{R}^{2}$ & \multicolumn{2}{|c|}{0.167} & \multicolumn{2}{|c|}{0.516} & \multicolumn{2}{|c|}{0.254} & \multicolumn{2}{|c|}{0.453} \\
\hline
\end{tabular}

OLS: 72 observations. 


\section{Average Contribution per Treatment}

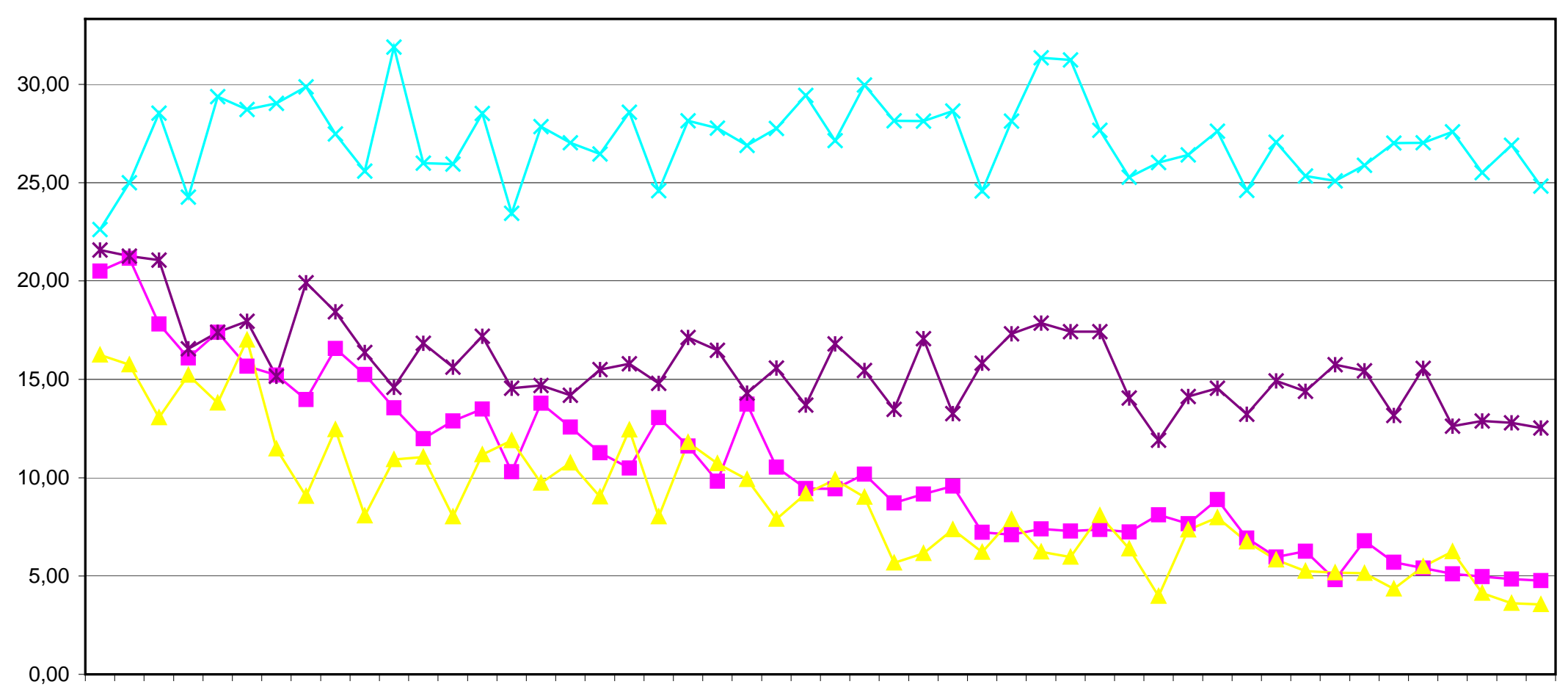

$122 \quad 3 \quad 4 \quad 5 \quad 6 \quad 7 \quad 8 \quad 91011121314151617181920212223242526272829303132333435363738394041424344454647484950$ Period

-Uniform Taxation

Uniform Rationing $\longrightarrow$ - Individualized Taxation $\rightarrow$ - Individualized Rationning

Fig.1. Evolution of the average contributions over time per treatment 


\section{APPENDIX A - Technical Appendix}

\section{1) Social optimum under uniform and individualized rationing}

Let us assume: $d=\frac{L}{S}, p=\frac{S}{N}, 0 \leq g_{i} \leq \frac{L}{N}$, and calculate the derivative of (8):

$\frac{\partial E U_{i}}{\partial g_{i}}=\frac{N-S}{N}\left[U_{i}^{\prime}\left(w_{i}+100-g_{i}-\frac{L}{S}\left(1-\frac{N g_{i}}{L}\right)-U_{i}^{\prime}\left(w_{i}+100-g_{i}\right)\right]\right.$

Hence, $\frac{\partial E U_{i}}{\partial g_{i}} \geq 0$ for all $g_{i} \leq \frac{L}{N}$ (and $=0$ for $\left.g_{i}=\frac{L}{N}\right)$.

Since $E U_{i}\left(g_{i}\right)$ is continuous in $g_{i}=\frac{L}{N}$ and has a maximum at this point, whether $0 \leq g_{i} \leq \frac{L}{N}$ or $g_{i} \geq \frac{L}{N}$, the social optimum corresponds to $g_{i}=\frac{L}{N}$.

2) Nash equilibrium under individualized rationing

Proposal 1: The Nash equilibrium necessarily comprises rationing if $\bar{g}_{-i} \leq L / N$.

Proof. We show that a no-rationing equilibrium is impossible if $\bar{g}_{-i} \leq L / N$. The best response of player $i$ consistent with full insurance would be $g_{i}=L-(N-1) \bar{g}_{-i} \equiv D$ and his utility of wealth would then be $U_{i}\left(w_{i}+100-D\right)$. The expected utility of $i$ under rationing if his contribution is $D$ is given by (13):

$E U_{i}(D)=(1-p) U_{i}\left(w_{i}+100-D\right)+p U_{i}\left(w_{i}+100-D-\frac{L}{S}+\frac{L}{D+\frac{S-1}{N-1}(L-D)} D\right)$

$E U_{i}(D) \geq U_{i}\left(w_{i}+100-D\right)$

implies: $-\frac{L}{S}+\frac{L}{D+\frac{S-1}{N-1}(L-D)} \geq 0$, which boils down to $\bar{g}_{-i} \leq L / N$.

Assuming that $\bar{g}_{-i} \leq L / N$, we now demonstrate that the best response under rationing is a contribution strictly lower than $D$ so that the Nash equilibrium implies rationing under such condition. To show this, we establish that the partial derivative of $E U_{i}$ is negative when $g_{i}=D$. From (13), we derive: 


$$
\begin{aligned}
\frac{\partial E U_{i}}{\partial g_{i}}= & -(1-p) U_{i}^{\prime}\left(w_{i}+100-g_{i}\right)+ \\
& p \frac{(S-1)(N-S) \bar{g}_{-i}^{2}}{\left(g_{i}+(S-1) \bar{g}_{-i}\right)^{2}} U_{i}^{\prime}\left(w_{i}+100-g_{i}-\frac{L}{S}+\frac{g_{i}+(N-1) \bar{g}_{-i}}{g_{i}+(S-1) \bar{g}_{-i}} g_{i}\right)
\end{aligned}
$$

Taking $g_{i}=D$ and $\bar{g}_{-i}=\frac{L-D}{N-1}$, we get:

$$
\begin{aligned}
& \frac{\partial E U_{i}}{\partial g_{i}}\left(g_{i}=D\right)=-\frac{N-S}{N} U_{i}^{\prime}(w+100-D)+ \\
& \frac{S}{N} \frac{(S-1)(N-S)}{[(N-1) D+(S-1)(L-D)]^{2}}(L-D)^{2} U_{i}^{\prime}\left(w_{i}+100-D-\frac{L}{S}+\frac{L}{D+\frac{S-1}{N-1}(L-D)} D\right) \\
& \leq-\frac{N-S}{N} U_{i}^{\prime}(w+100-D)+\frac{S}{N} \frac{(S-1)(N-S)}{[(N-1) D+(S-1)(L-D)]^{2}}(L-D)^{2} U_{i}^{\prime}\left(w_{i}+100-D\right)
\end{aligned}
$$

if $\bar{g}_{-i} \leq L / N$ and $U_{i}^{\prime \prime}<0$. For showing that $\frac{\partial E U_{i}}{\partial g_{i}}\left(g_{i}=D\right)<0$, it is sufficient to prove that

$\frac{S(S-1)}{[(N-1) D+(S-1)(L-D)]^{2}}(L-D)^{2}<1$,

or, after some rearrangement of terms

$$
(S-1)\left[L^{2}-2 N L D+S D^{2}\right]<(N-S)^{2} D^{2}
$$

Since the term between brackets is negative if $D / L \in[1 / N, 1]$, the above inequality holds for all admissible values of $D / L$ conditional on $\bar{g}_{-i} \leq L / N$, q.e.d.

Therefore, the Nash equilibrium must comprise rationing.

Proposal 2: The Nash equilibrium with individualized rationing corresponds to a positive contribution.

Proof. Return to expression (A.2.1) and take: $g_{i}=0$ :

$\frac{\partial E U_{i}}{\partial g_{i}}(0)=-(1-p) U_{i}^{\prime}\left(w_{i}+100\right)+p U_{i}^{\prime}\left(w_{i}+100-\frac{L}{S}\right) \frac{(N-S)}{S-1}$

This derivative is positive when: $p=\frac{S}{N}$, if $U_{i}^{\prime \prime} \leq 0$ for all values of $\bar{g}_{-i}$. Thus, given all the other contributions, the contribution of any risk averse agent that maximizes his expected utility (14) must be strictly positive. Since this result does not depend on the value taken on by the other 
contributions $^{16}$, the Nash equilibrium comprises rationing, but nevertheless a positive contribution from all the risk averse agents.

\footnotetext{
${ }^{16}$ Under the condition that the two rationing conditions described in (13) are met. They are always met when neighbouring a set of null contributions. We are therefore certain that the set of rationing situations includes this neighbourhood and that the equilibrium with rationing always holds positive contributions.
} 


\section{APPENDIX B - INSTRUCTIONS}

\section{TREATMENT: UNIFORM TAXATION}

You are participating to an experiment in which we ask you to make decisions. Each participant makes her (his) decisions individually in front of her (his) computer.

At the beginning of the experiment, you are given an initial capital of 110 tokens. During the experiment, you can earn an additional amount of money. The final amount of earnings you will get depends on your decisions and on the other participants' decisions. At the end of the experiment, your earnings in tokens will be converted into Canadian $\$$ according to the following conversion rate: 300 tokens $=\$ 1.55$. You will be paid individually in a separate room to preserve the confidentiality of your earnings.

Each period, you will form a group with the other 11 participants. Communication between participants is forbidden and you are asked not to react loudly during the course of the experiment.

The experiment has 50 periods. Each period is independent of the others.

At the beginning of each period, you will receive 100 tokens. You can contribute to a common pool intended to cover the losses that will randomly strike 4 persons among the 12 group members. Each of the 4 afflicted members loose their 100 tokens. The common pool is equal to the sum of the contributions by each group member. Three situations can occur:

a The common pool is of 400 tokens. This allows all 4 afflicted members to regain their 100 lost tokens each.

a The common pool is greater than the sum of the lost tokens. In this case, the 4 afflicted members regain their 100 lost tokens and the surplus is not reported to the next period.

- The common pool is insufficient to allow the 4 afflicted members to regain their 100 lost tokens. In this case, a deduction is carried out. The amount of this deduction is equal to the difference between the common pool and the total of 400 lost tokens by the 4 afflicted members. This deduction added to the common pool allows the 4 afflicted members to regain their lost tokens. Each of the 12 group members pays 1/12 of this deduction. Furthermore, this deduction leads to an additional cost for each group member, increasing with the importance of the deficit, as described in the table below.

Table of your additional deduction cost

Class of deficit in tokens Individual additional deduction cost in tokens

\begin{tabular}{cc}
\hline 1 to 130 & 5 \\
\hline 131 to 202 & 8 \\
\hline 203 to 255 & 13 \\
\hline 256 to 298 & 18 \\
\hline 299 to 336 & 23 \\
\hline 337 to 370 & 28 \\
\hline 371 to 400 & 33 \\
\hline
\end{tabular}

\section{Rules for each period}

You will be given 100 tokens.

You choose, with the help of a cursor, the number of these tokens between 0 and 100 that you allocate to the common pool. This choice is validated as soon as you click on the OK button.

The computer then gives you 5 pieces of information:

- You are or not one of the 4 persons who each loose their 100 tokens 
- The total amount of the common pool

- If applicable, the total amount of the deficit

- In case of a deficit, the amount of your total deduction

- Your earnings in tokens for this period.

A new period, independent of the previous ones, is automatically shown. Each period, you receive a new allocation of 100 tokens. A new random draw determines the afflicted members. The conditions described above continue to apply.

\section{How we determine your earnings}

During a period, your earnings are calculated by the computer the following way:

Your 100 tokens

- the tokens that you allocate to the common pool

- the tokens that you lost if you were afflicted

+ the reimbursement of your lost tokens if you are afflicted, and, if required,

- your individual deduction

- your additional deduction cost

At the end of the experimental session, your total earnings are calculated by the sum of your earnings for each of the 50 periods, plus the initial capital. It is this amount that will be converted in Canadian $\$$.

\section{Additional information}

Before we begin the experimental session, we will ask you to answer a few comprehension questions on these instructions. As soon as you have all answered correctly all the questions, you will be asked to provide us some details on your age, gender, level and field of education, university or school currently frequented or your current work situation, and if you have participated to an experiment before. This information will remain anonymous. The experiment will then begin.

After taking place in front of your computer, please raise your hand if you have questions on these instructions. We will come and answer your questions privately.

\section{TREATMENT: INDIVIDUALIZED RATIONING}

You are participating to an experiment in which we ask you to make decisions. Each participant makes her (his) decisions individually in front of her (his) computer.

At the beginning of the experiment, you are given an initial capital of 110 tokens. During the experiment, you can earn an additional amount of money. The final amount of earnings you will get depends on your decisions and on the other participants' decisions. At the end of the experiment, your earnings in tokens will be converted into Canadian $\$$ according to the following conversion rate: 300 tokens $=\$ 1.55$. You will be paid individually in a separate room to preserve the confidentiality of your earnings.

Each period, you will form a group with the other 11 participants. Communication between participants is forbidden and you are asked not to react loudly during the course of the experiment.

The experiment has 50 periods. Each period is independent of the others.

At the beginning of each period, you will receive 100 tokens. You can contribute to a common pool intended to cover the losses that will randomly strike 4 persons among the 12 group members. Each of the 4 afflicted members loose their 100 tokens. The common pool is equal to the sum of the contributions by each group member. Three situations can occur:

a The common pool is of 400 tokens. This allows all 4 afflicted members to regain their 100 lost tokens each. 
a The common pool is greater than the sum of the lost tokens. In this case, the 4 afflicted members regain their 100 lost tokens and the surplus is not reported to the next period.

- The common pool is insufficient to allow the 4 afflicted members to regain their 100 lost tokens. In this case, each one of the 4 afflicted members receives a reimbursement that depends on two elements: his contribution to the common pool with respect to the other afflicted members in the group and the total amount of the common pool. The common pool is thus redistributed to the 4 afflicted members proportionally to how much each has contributed with respect to the other afflicted members and within the limit of their initial loss.

\section{Rules for each period}

You will be given 100 tokens.

You choose, with the help of a cursor, the number of these tokens between 0 and 100 that you allocate to the common pool. This choice is validated as soon as you click on the OK button.

The computer then gives you 5 pieces of information:

- You are or not one of the 4 persons who each loose their 100 tokens

- The total amount of the common pool

- If applicable, the total amount of the deficit

- The number of tokens that are allocated to you if you are afflicted

- Your earnings in tokens for this period.

A new period, independent of the previous ones, is automatically shown. Each period, you receive a new allocation of 100 tokens. A new random draw determines the afflicted members. The conditions described above continue to apply.

\section{How we determine your earnings}

During a period, your earnings are calculated by the computer the following way:

Your 100 tokens

- the tokens that you allocate to the common pool

- the tokens that you have lost if you are afflicted

and, if the common pool is sufficient

+ the reimbursement of your lost tokens if you are afflicted

or, if the common pool is insufficient

+ the reimbursement proportionally to how much each has contributed with respect to the other afflicted members and within the limit of your initial loss.

At the end of the experimental session, your total earnings are calculated by the sum of your earnings for each of the 50 periods, plus the initial capital. It is this amount that will be converted in Canadian $\$$.

\section{Additional information}

Before we begin the experimental session, we will ask you to answer a few comprehension questions on these instructions. As soon as you have all answered correctly all the questions, you will be asked to provide us some details on your age, gender, level and field of education, university or school currently frequented or your current work situation, and if you have participated to an experiment before. This information will remain anonymous. The experiment will then begin.

After taking place in front of your computer, please raise your hand if you have questions on these instructions. We will come and answer your questions privately. 


\section{APPENDIX C - DESCRIPTIVE STATISTICS}

\begin{tabular}{|c|c|c|c|c|c|c|c|c|c|c|}
\hline \multirow[t]{2}{*}{ Definition } & \multicolumn{2}{|c|}{ All treatments } & \multicolumn{2}{|c|}{ Uniform Taxation } & \multicolumn{2}{|c|}{ Uniform Rationing } & \multicolumn{2}{|c|}{ Individualized Rationing } & \multicolumn{2}{|c|}{ Individualized Taxation } \\
\hline & Average & $\begin{array}{c}\text { Std } \\
\text { deviation }\end{array}$ & Average & $\begin{array}{c}\text { Std } \\
\text { deviation }\end{array}$ & Average & $\begin{array}{c}\text { Std } \\
\text { deviation }\end{array}$ & Average & $\begin{array}{c}\text { Std } \\
\text { deviation }\end{array}$ & Average & Std deviation \\
\hline Individual contribution to the common pool & 15.54 & 19.61 & 10.50 & 15.26 & 8.77 & 16.55 & 15.74 & 17.77 & 27.16 & 22.55 \\
\hline$\%$ null contributions & 33.0 & & 38.0 & & 53.0 & & 28.0 & & 14.0 & \\
\hline$\%$ optimal contributions & 5.0 & & 4.0 & & 1.0 & & 4.0 & & 10.0 & \\
\hline Contribution to the common pool & 186.52 & 109.62 & 126.06 & 73.78 & 105.24 & 70.62 & 188.77 & 63.96 & 326.01 & 61.79 \\
\hline Value of the pool - 400 to compensate victims & -213.48 & 109.61 & -273.94 & 73.78 & -294.76 & 70.62 & -211.23 & 63.96 & -73.99 & 61.79 \\
\hline Rate of periods with a deficit & 0.97 & 0.18 & 1.00 & 0.00 & 1.00 & 0.00 & 0.99 & 0.08 & 0.87 & 0.33 \\
\hline $\begin{array}{l}\text { Sum of the others' contributions in the } \\
\text { previous period }\end{array}$ & 171.89 & 101.65 & 116.84 & 69.04 & 97.64 & 66.63 & 173.76 & 61.00 & 299.33 & 60.16 \\
\hline $\begin{array}{l}\text { Number of disasters achieved in } t \text { minus the } \\
\text { anticipated number }\end{array}$ & 0.98 & 2.40 & 0.98 & 2.42 & 0.98 & 2.18 & 0.98 & 2.40 & 0.98 & 2.58 \\
\hline Participants earnings in tokens & 60.76 & 28.16 & 48.26 & 15.88 & 66.55 & 39.01 & 66.57 & $\begin{array}{c}32.85 \\
4.78\end{array}$ & 61.69 & 9.79 \\
\hline Participants' age & 24.12 & 5.25 & 23.99 & 5.67 & 23.54 & 4.57 & 24.87 & & 24.07 & 5.77 \\
\hline$\%$ male participants & 67.0 & & 65.0 & & 67.0 & & 76.0 & & 58.0 & \\
\hline $\begin{array}{l}\% \text { participants who have already participated } \\
\text { to an experiment }\end{array}$ & 79.0 & & 87.0 & & 85.0 & & 75.0 & & 69.0 & \\
\hline$\%$ participants who chose the lottery & 62.0 & & 64.0 & & 64.0 & & 60.0 & & 60.0 & \\
\hline$\%$ Workers & 5.0 & & 5.0 & & 4.0 & & 6.0 & & 6.0 & \\
\hline$\%$ Unemployed & 4.0 & & 7.0 & & 3.0 & & 3.0 & & 3.0 & \\
\hline$\%$ Students & 91.0 & & 87.0 & & 94.0 & & 92.0 & & 92.0 & \\
\hline$\%$ Graduated & 19.0 & & 18.0 & & 21.0 & & 21.0 & & 15.0 & \\
\hline$\%$ Students with a mathematical background & 80.0 & & 81.0 & & 79.0 & & 83.0 & & 78.0 & \\
\hline
\end{tabular}

Note: Statistics based on 3800 observations per treatment. 